\title{
Effects of annealing and firing in wet hydrogen on the dielectric breakdown strengths of alumina ceramics
}

\author{
Jishi DU ${ }^{a,{ }^{*}}$, Binghua $\mathrm{TANG}^{a}$, Wei LIU ${ }^{a}$, Tao ZHANG ${ }^{a, b}$, \\ Jiagen $\mathrm{PENG}^{a}, \mathrm{Hu} \mathrm{CHEN}^{a}$, Yangjun $\mathrm{LEI}^{a}$ \\ ${ }^{a}$ Institute of Electronic Engineering, China Academy of Engineering Physics, Mianyang 621900, China \\ ${ }^{b}$ Department of Materials Science, Sichuan University, Chengdu 610064, China
}

Received: November 15, 2019; Revised: December 24, 2019; Accepted: December 26, 2019

(C) The Author(s) 2019.

\begin{abstract}
Annealing and firing in wet hydrogen are widely used steps in the processing alumina-ceramic insulators that may affect their dielectric breakdown strengths (DBS). In this study, the effects of annealing (at $1300{ }^{\circ} \mathrm{C}$ for $7 \mathrm{~h}$ ) and firing in wet hydrogen on the DBS of alumina ceramics (all sintered at $1650{ }^{\circ} \mathrm{C}$ ) were studied, and the underlying mechanisms were analyzed by material characterizations. Annealing reduced the DBS of the $95 \%$ alumina ceramics due to the inter-granular phase crystallization, and the reduction in the DBS could be correlated to the reduction in mechanical strength. In contrast, annealing improved the DBS of the $99 \%$ alumina ceramic without intergranular phase transformation. Firing in wet hydrogen at $1500{ }^{\circ} \mathrm{C}$ caused the DBS increment, which can be ascribed to the reduction in the concentrations of point defects and electrical carriers.

Keywords: alumina ceramic; dielectric breakdown strength (DBS); inter-granular phase crystallization; firing in wet hydrogen
\end{abstract}

\section{Introduction}

The alumina ceramics are commonly used as insulation materials, mainly because of their low prices, capacity to be easily shaped, high flexural strengths, good stability at high temperatures, low dielectric loss, and their high dielectric breakdown strengths (DBS). Annealing and firing in wet hydrogen are widely carried out in processing alumina-ceramic insulators. For example, alumina-ceramic insulators are always required to be annealed at a temperature lower than the sintering temperature to burn away any possible contaminations on their surfaces and diminish the residual stress

* Corresponding author.

E-mail: flash6669@163.com introduced by the grinding. The alumina-ceramic insulators are heated in wet hydrogen at a high temperature when sealed with the metal electrodes [1]. Annealing and firing in wet hydrogen may induce some reactions in alumina ceramics, which may affect the DBS.

Annealing could induce an inter-granular phase transformation in alumina ceramics. Chemical impurities in raw alumina powders cannot be eliminated, and some chemical impurities are intentionally added in order to optimize the performances of alumina ceramics and promote sintering. Some of the chemical impurities have very low solubilities in the alumina lattice. Park and Yoon [2] found that the solubility limit of $\mathrm{Ca}$ in the alumina lattice was only about $20 \mathrm{ppm}$, while the solubility limit of $\mathrm{Si}$ in the alumina lattice was several 
hundreds of ppm. The excessive chemical impurities always segregate at the grain boundaries, and sometimes exist in the form of liquid phases during sintering [3,4]. Powell-Dogan et al. [5-7] reported that most of the sintering aids $\left(\mathrm{MgO}, \mathrm{SiO}_{2}, \mathrm{CaO}\right)$ were present at the grain boundaries as continuous amorphous or glassy phases in a $96 \%$ alumina ceramic, and that the inter-granular amorphous phases would crystallize when the alumina ceramic was annealed at a relatively modest temperature. The inter-granular phase crystallization induced by annealing may change the DBS of alumina ceramics. Liebault et al. [8] reported that annealing at $1200{ }^{\circ} \mathrm{C}$ improved the DBS of two alumina ceramics with $5 \%-8 \%$ sintering aids, and they reasoned that the crystalline phases developed on the surface were more able to trap electrical carriers to prohibit the dielectric breakdown (DB). However, though Touzin et al. [9] argued that a high content of crystalline anorthite did not favor the DBS of alumina ceramics at room temperature, they did not provide any evidence to support their argument. As no more reports on the effect of inter-granular phase crystallization on the DBS of alumina ceramics were found, this issue remains controversial.

When the alumina ceramics are processed in a different atmosphere, their electrical conductivities can change due to the varying concentrations of point defects. Pappis and kingery [10] found that the electrical conductivity of alumina increased at both high and low oxygen pressures, and they reasoned that the concentrations of electrical carriers changed with the oxygen pressure as a result of the changing concentrations of point defects. Miranzo et al. [11] reported that sintering in a $\mathrm{CO} / \mathrm{CO}_{2}$ atmosphere improved the electrical conductivity of an alumina ceramic at $600{ }^{\circ} \mathrm{C}$ by five orders of magnitude. The DB and surface flashover were both correlated to the transport of electrical carriers [12]. Jaitly et al. [13] reported that firing in wet hydrogen reduced the surface flashover voltages of alumina ceramics, and improved the surface electrical resistances. However, the effect of firing in wet hydrogen on the DBS of alumina ceramics has not been reported.

In this study, two $95 \% \mathrm{SiO}_{2}-\mathrm{CaO}$ co-doped alumina ceramics were sintered, and then quenched to keep the inter-granular phases amorphous. Annealing was performed at a modest temperature for a long time to induce the crystallization of the amorphous inter-granular phases. The DBS was measured before and after annealing. For comparison, a 99\% alumina ceramic was treated in the same way and the effect of annealing on the DBS without inter-granular phase transformation was analyzed. The aforementioned three alumina ceramics were all heated in wet hydrogen at a high temperature for a short time to investigate the effect of firing in wet hydrogen on the DBS of alumina ceramics. Densities, the roughness of the surfaces, reflectance spectra, crystalline phases, bending strengths, surface and fracture microstructures, chemical compositions, electrical conductivities, dielectric constants, and losses of the samples before and after treatments were characterized to study the mechanisms behind the effects.

\section{Experimental}

\section{1 Sample preparation}

Three alumina ceramics were named as "A95", "B95", and "A99". The chemical composition of A95 was: $94.7 \mathrm{wt} \% \mathrm{Al}_{2} \mathrm{O}_{3}, 2.62 \mathrm{wt} \% \mathrm{SiO}_{2}, 2.16 \mathrm{wt} \% \mathrm{CaO}, 0.08$ $\mathrm{wt} \% \mathrm{MgO}, 0.09 \mathrm{wt} \% \mathrm{Na}_{2} \mathrm{O}$, and $0.05 \mathrm{wt} \% \mathrm{Fe}_{2} \mathrm{O}_{3}$. $\mathrm{A} 99$ contained more than $99 \mathrm{wt} \% \mathrm{Al}_{2} \mathrm{O}_{3}$ with a little $\mathrm{Y}_{2} \mathrm{O}_{3}$. A95 and A99 sheets with a diameter of $30 \mathrm{~mm}$ were shaped by dry pressing in a tungsten-steel die with an axial pressure of $100 \mathrm{MPa}$, and then repressed by cold-isostatic pressing at $170 \mathrm{MPa}$. The chemical composition of $\mathrm{B} 95$ was: $94.5 \mathrm{wt} \% \mathrm{Al}_{2} \mathrm{O}_{3}, 2.2 \mathrm{wt} \%$ $\mathrm{SiO}_{2}$, and $3.3 \mathrm{wt} \% \mathrm{CaO}$. Sheets of $\mathrm{B} 95$ with a diameter of $40 \mathrm{~mm}$ were prepared by the low-pressure injection molding technique and the partial wick-debinding technique $[14,15]$.

The green bodies were sintered in a muffle furnace heated by $\mathrm{MoSi}_{2}$ in air following the sintering temperature curve shown in Fig. 1. During the sintering, all the sheets were placed on the sintered $99 \%$ alumina plates, on which some 60 mesh corundum powder was sprinkled. The thicknesses of the as-sintered A99, A95, and B95 sheets were 2.51, 2.37, and $3.61 \mathrm{~mm}$, respectively, and the diameters of the as-sintered A99, A95, and B95 sheets were about 25, 26, and $36 \mathrm{~mm}$, respectively. All the as-sintered sheets were polished in vibrating alumina ceramic shivers at $1500 \mathrm{~Hz}$ for $1 \mathrm{~h}$. The B95 sheets were machined into $1.98 \mathrm{~mm}$-thick sheets by grinding both surfaces using a grind wheel of 400 mesh diamond.

After sintering, the temperature dropped to about $1250{ }^{\circ} \mathrm{C}$ within $1 \mathrm{~h}$, so it was believed that the liquid 




Fig. 1 Sintering temperature curve, the annealing temperature curve, and the temperature curve of firing in wet hydrogen.

phases in A95 and B95 during sintering were frozen into certain types of amorphous inter-granular phases. After sintering and polishing, five additional processes were carried out: surface grinding, annealing, firing in wet hydrogen, polishing, and quenching. Annealing was conducted in a muffle furnace heated by $\mathrm{MoSi}_{2}$ in air following the temperature curve in Fig. 1. Firing in wet hydrogen was conducted in a molybdenum-heating oven following the temperature curve in Fig. 1, and when the temperature was lower than $900{ }^{\circ} \mathrm{C}$, nitrogen was pumped into the oven, while wet hydrogen with a dew point of $30{ }^{\circ} \mathrm{C}$ was pumped into the oven when the temperature was higher than $900{ }^{\circ} \mathrm{C}$. Some of the annealed A99 sheets were polished by the aforementioned method for $2 \mathrm{~h}$ in order to analyze the effect of polishing on the DBS. A few of the annealed B95 samples were heated to $1650{ }^{\circ} \mathrm{C}$ at a rate of $150{ }^{\circ} \mathrm{C} / \mathrm{h}$, maintained at $1650{ }^{\circ} \mathrm{C}$ for $10 \mathrm{~min}$, and then quenched to $1250{ }^{\circ} \mathrm{C}$ within $1 \mathrm{~h}$ in order to analyze the change in DBS when the inter-granular phase crystallization was eliminated. All the processed samples were washed in deionized water for $1 \mathrm{~h}$ by a supersonic washer, and then dried at $100{ }^{\circ} \mathrm{C}$ in a drying oven for $24 \mathrm{~h}$. The samples are identified by the names of the alumina ceramics and the order in which the additional processes used in their preparation were carried out. For example, "B95-G-A-Q" is the name of the B95 sheets that were processed by surface grinding, annealing, and quenching, in that order. In the naming convention that was followed, "G", "A", "FWH", "P", and "Q" are abbreviations for surface grinding, annealing, firing in wet hydrogen, polishing, and quenching, respectively.

The main properties of the raw materials and more information on the sample preparation can be found in the Electronic Supplementary Material (ESM).

\section{2 Dielectric breakdown test and material characterizations}

The DB test was conducted at room temperature. A spherical-to-planar electrode set-up was used. The spherical electrode was a stainless steel ball with a diameter of $4.00 \pm 0.005 \mathrm{~mm}$. The planar electrode was a brass cylinder with a diameter of $4 \mathrm{~mm}$ that had a fillet with a radius of $0.5 \mathrm{~mm}$ at the rim. More details about the electrode set-up can be found in the ESM. During the DB test, the electrode set-up and the sample were immersed in insulation oil to avoid the surface flashover. Before use, the insulation oil was cleaned, degassed, and dried. An AC high voltage power supply of $50 \mathrm{~Hz}$ was used in the DB test, and the ramp rate was $1 \mathrm{kV} / \mathrm{s}$. The DB voltage $V_{\mathrm{b}}$ was determined by measuring the abrupt increase in the current, following the specifications of ASTM Standard D149-97a [16]. The occurrence of a DB was accompanied by a sparkle and an explosion. The nominal DBS $E_{\mathrm{b}}$ (DBS for short in this paper) was calculated as: $E_{\mathrm{b}}=V_{\mathrm{b}} / t$, where $t$ was the thickness of the sample $(\mathrm{mm})$. For each condition, five sheets were used to measure the DBS, and four points on each sheet were selected for the measurement. After each DB test, the stainless steel ball was rolled a little to ensure that its surface in contact with the sample was fresh. Each stainless steel ball was used as the spherical electrode 20 times, and no influence of the use time on the measured values was found. It is worth mentioning that it is hard to get the real electric field strength when the DB of the alumina ceramic occurred by the simulation methods, because the DB of the insulation oil occurred prior to the $\mathrm{DB}$ of the alumina ceramics; this changed the dielectric constant and the distribution of space charges. More discussions on the DB test can be found in the ESM.

The volume densities were measured using the Archimedes method in water at room temperature. Surface roughness $(S z)$ was measured by a measuring laser microscope. The crystalline phases were analyzed by X-ray diffraction (XRD, $\mathrm{Cu} \mathrm{K} \alpha$ ). Surface and fracture microstructures were examined by scanning electron microscope (SEM, back scattered electron), and the chemical compositions at certain points were analyzed by an energy dispersive spectrometer (EDS). A three-point method was used to measure the bending strengths of B95 samples, and the experimental procedure can be found in the ESM. Reflectance spectra of the wavelengths in the range of 200-2500 $\mathrm{nm}$ were measured using a UV-Vis-R spectrometer with an 
integrating sphere. The frequency dependence of the dielectric constant and the dielectric loss was tested using a precision impedance analyzer from $1 \mathrm{kHz}$ to 2 $\mathrm{MHz}$ at room temperature, and gold coatings of diameter $13 \mathrm{~mm}$ were sputtered onto the samples. Chemical compositions of some samples were analyzed by X-ray photoelectron spectroscopy (XPS). The DC electrical conductivities at $3 \mathrm{kV}$ were measured, and more details about these measurements can be found in the ESM.

\section{Results and discussion}

\section{1 Dielectric breakdown strengths of all the samples}

Figure 2 displays the measured DBS data sorted in ascending order and their Weibull distribution fitting. Annealing improved the DBS of the $99 \%$ alumina as shown in Fig. 2(a), while it reduced the DBS of 95\% alumina ceramics, as shown in Figs. 2(b) and 2(c). Quenching improved the DBS of B95-G-A to a higher level that was even higher than the DBS of B95-G, as shown in Fig. 2(c). Firing in wet hydrogen improved the DBS of alumina ceramics. For the ground samples, A99-G had the highest DBS compared to A95-G and B95-G, as shown in Figs. 2(c) and 2(d). Polishing did not reduce the average DBS of A99-A, but it increased the standard deviation as shown in Fig. 2(a). It should be mentioned that the measured DBS data of the $95 \%$ alumina ceramics after annealing could not be well fitted to the Weibull distribution, as shown in Figs. 2(b) and 2(c), and this was different from the previous reports, in which the DBS data could be fitted to the Weibull distribution well $[17,18]$. Although it seems that the large values of the data of A95-A and B95-G-A damage the fitting to the Weibull distribution, the remaining data cannot be fitted to the Weibull distribution well if the large values are excluded. Although much research work has been done on the distribution of the DBS data, what influences the distribution of the DBS data of alumina ceramics is still unclear.

Annealing and firing in wet hydrogen had almost no
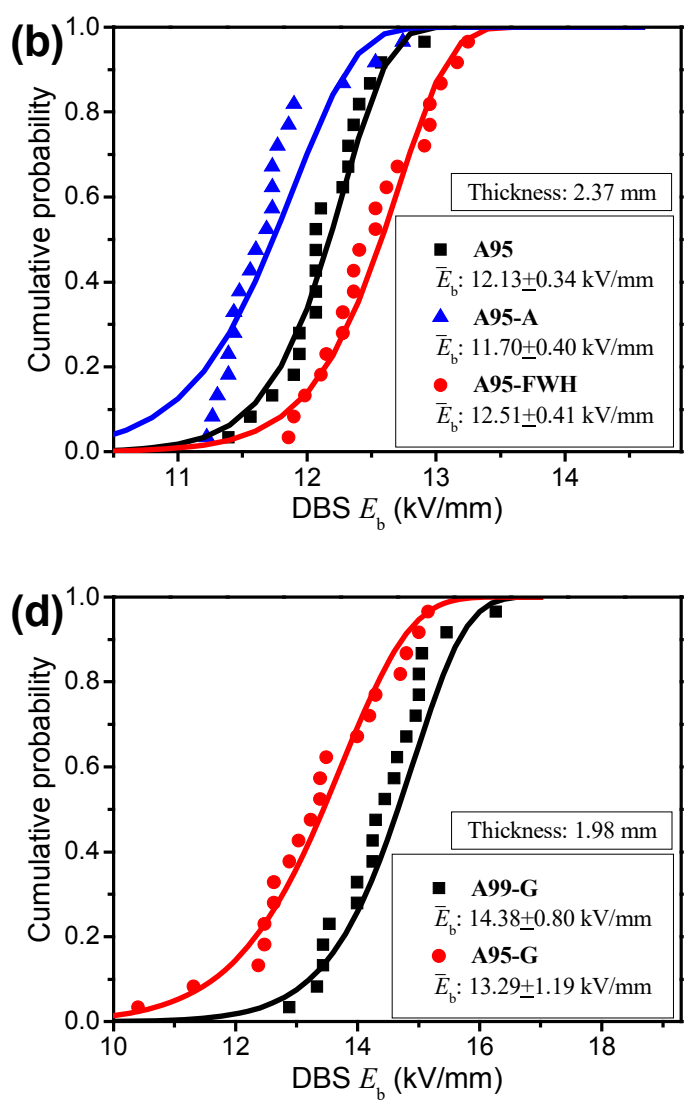

Fig. 2 Measured DBS $E_{\mathrm{b}}$ data sorted in ascending order and the Weibull distribution fitting (lines): the cumulative probability corresponding to the $i$-th value sorted in ascending order is equal to $(i-0.3) /(n+0.4)$, where $n$ is the total number of the values. The inset data $\bar{E}_{\mathrm{b}}$ is the average value of $E_{\mathrm{b}}$ with the standard deviation. 
effects on the densities (Table 1). Therefore, the effects of annealing and firing in wet hydrogen on the DBS of alumina ceramics could not be ascribed to the effects on the densities. No evident relationship between $S z$ (ESM) and the DBS was found. The effects of annealing and firing in wet hydrogen on the DBS of the three alumina ceramics were also not attributed to the effects on the dielectric constants and losses (ESM).

\section{2 Analyses of the underlying mechanisms behind the effects of annealing}

Annealing had no effects on the phases of A99, while it made the glassy phase in the $95 \%$ alumina ceramics crystallize into gehlenite $\left(2 \mathrm{CaO} \cdot 3 \mathrm{SiO}_{2} \cdot 2 \mathrm{Al}_{2} \mathrm{O}_{3}\right)$ and anorthite $\left(\mathrm{CaO} \cdot 2 \mathrm{SiO}_{2} \cdot 2 \mathrm{Al}_{2} \mathrm{O}_{3}\right)$. Quenching diminished the inter-granular phase crystallization, as shown by the XRD patterns in Fig. 3. Our results were consistent with the results from the work completed by PowellDogan et al. [5-7]. The inter-granular crystalline phases in $95 \%$ alumina ceramics were flake-like and rich in $\mathrm{Si}$ and $\mathrm{Ca}$ that were eliminated by the quenching, as shown by the SEM images and EDS results in Fig. 4. It should be mentioned that $\mathrm{Si}$ and $\mathrm{Ca}$ existed on the surface of A95 and B95-G-A-Q, although there were no flake-like structures on the surface of annealed $95 \%$ alumina ceramics. The existence of $\mathrm{Si}$ and $\mathrm{Ca}$ on the

\begin{tabular}{|c|c|c|c|}
\hline Sample Condition & As-sintered & Annealed & $\begin{array}{c}\text { Fired in wet } \\
\text { hydrogen }\end{array}$ \\
\hline A99 & $3.921 \pm 0.038$ & $3.919 \pm 0.042$ & $3.926 \pm 0.029$ \\
\hline A95 & $3.714 \pm 0.084$ & $3.711 \pm 0.053$ & $3.715 \pm 0.075$ \\
\hline B95-G & $3.668 \pm 0.047$ & $3.663 \pm 0.039$ & $3.665 \pm 0.051$ \\
\hline
\end{tabular}



Fig. 3 XRD patterns of $95 \%$ alumina ceramics before and after annealing and quenching. surfaces of A95 and B95-G-A-Q was proven by the XPS spectra shown in Fig. 5, in which, the peaks corresponding to $\mathrm{Si}$ and $\mathrm{Ca}$ could be detected. Considering that the detection depth of XPS is only several nanometers, it can be concluded that $\mathrm{Si}$ and $\mathrm{Ca}$ always existed on the surface of the $95 \%$ alumina ceramics before and after annealing and quenching. Surface grinding crushed the grains on the surface, and the fragments on the surface coarsened into small grains, as shown in Fig. 4. XRD and EDS showed that the bright spots in $\mathrm{A} 99$ were yttrogarnet $\left(\mathrm{Y}_{3} \mathrm{Al}_{5} \mathrm{O}_{12}\right)(\mathrm{ESM})$. Firing in wet hydrogen had no effects on the phases and the microstructures of all the three alumina ceramics except for the slight healing of the ground surface of B95-G. More XRD patterns and SEM images are shown in the ESM.

Comparing the results in Figs. 2-4, it can be concluded that it might be the inter-granular phase crystallization that reduced the DBS of the $95 \%$ alumina ceramics after annealing, and hence it is better to avoid the intergranular phase crystallization when the alumina-ceramic insulators are annealed. The result in this study was consistent with the results from the work of Touzin et al. [9] which argued that an alumina ceramic with more crystalline inter-granular phases had a lower DBS than the alumina ceramic with more glassy inter-granular phases. The result in this study contradicted Ref. [8]. Liebault et al. [8] did not analyze the phases in those two alumina ceramics before and after annealing; therefore, whether inter-granular phase crystallization had occurred in their experiment is unclear. Further, it was not appropriate to state that inter-granular phase crystallization improved the DBS of the alumina ceramics.

The model of DB based on mechanical properties $[19,20]$ is capable of explaining why the inter-granular phase crystallization decreased the DBS of the $95 \%$ alumina ceramics. The inter-granular phase crystallization in alumina ceramics was found to result in a remarkable improvement in the toughness and to lessen the mechanical strengths [21,22]. Tomaszewski [21] attributed the reduction to the micro-cracks generated by the mismatch between the alumina matrix and the crystalline inter-granular phases. Jouini et al. [23] found that the microcracks induced by pre-stress led to a reduction in the DBS of an alumina ceramic. Annealing decreased the bending strength of B95, while the quenching which followed annealing recaptured the bending strength, as shown in Fig. 6. The micro-cracks generated by the inter-granular phase crystallization 


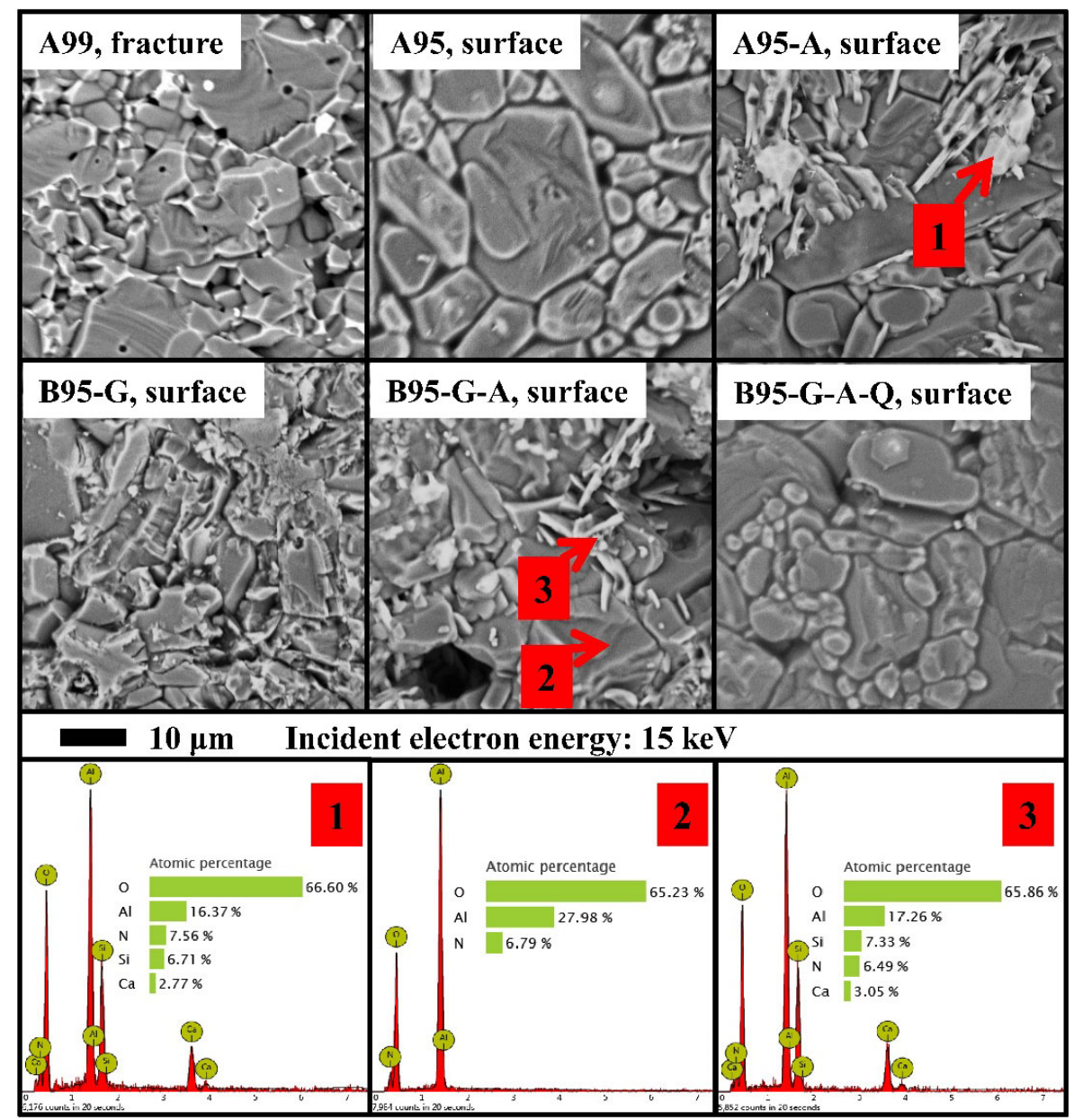

Fig. 4 SEM (back scattered electron) images: the chemical compositions at three points were analyzed by EDS.

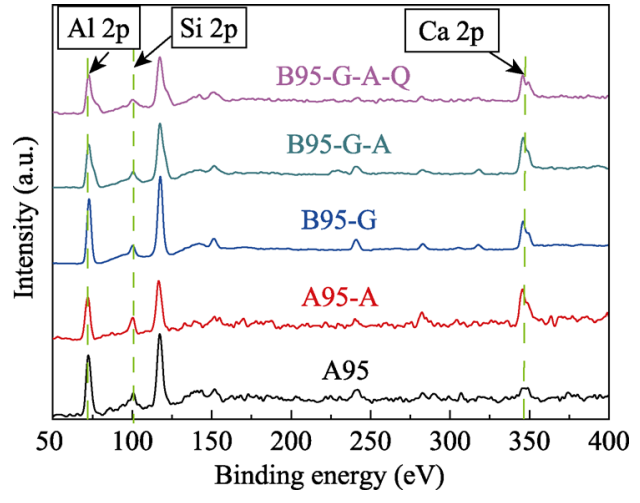

Fig. 5 XPS spectra of the $95 \%$ alumina ceramics before and after annealing and quenching.

improved the propagation of the DB channel and reduced the DBS of the $95 \%$ alumina ceramics.

However, the shape parameters of the Weibull distribution fitting in the $\mathrm{DB}$ test were much higher than the corresponding shape parameters of Weibull distribution fitting in the bending strength measurement, as listed in Table 2, and this difference was also

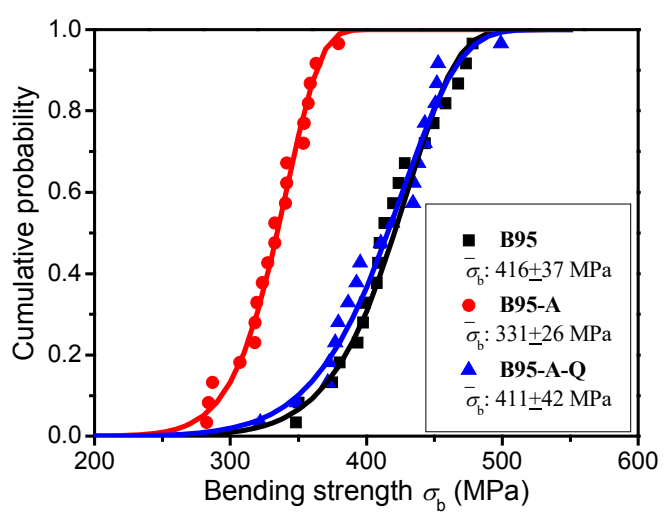

Fig. 6 Measured bending strength $\sigma_{\mathrm{b}}$ data of B95 samples sorted in ascending order and the Weibull distribution fitting (lines). The inset data $\bar{\sigma}_{\mathrm{b}}$ is the average value of $\sigma_{\mathrm{b}}$ with the standard deviation.

discovered by Neusel et al. [18]. Additionally, the Weibull distribution fitting of the measured bending strength data of B95-A was much better than the Weibull distribution fitting of the measured DBS data of B95-G-A. This can be observed by comparing Fig. 2(c) 
Table 2 Shape parameters of the Weibull distribution fitting in the dielectric breakdown test and the bending strength measurement of $\mathrm{B} 95$ samples

\begin{tabular}{cccc}
\hline Sample in dielectric breakdown test & B95-G & B95-G-A & B95-G-A-Q \\
\hline Shape parameter $(95 \%$ confidence) & $22.63(16.58-30.88)$ & $23.84(17.78-31.98)$ & $16.25(11.62-22.73)$ \\
\hline \hline Sample in bending strength measurement & B95 & B95-A & B95-A-Q \\
\hline Shape parameter $(95 \%$ confidence $)$ & $12.64(9.03-17.72)$ & $14.59(10.40-20.47)$ & $10.90(7.84-15.16)$ \\
\hline
\end{tabular}

with Fig. 6. As a result, the correlation between the DB and the mechanical fracture is not so simply through the identical defects, but may be attributed to the fact that $\mathrm{DB}$ and mechanical fracture are both dependent on the energetics of the mechanically strained lattice [12]. The strained lattice has a higher energy level, and is easier to be broken than the non-strained lattice. In the DB process, when high electric field is applied, the incident electron excites the electrons from the valance band to the conduction band at the strained lattice easier than at the non-strained lattice, so the happening of the avalanche DB is more likely in the alumina ceramics full of strained lattice. Much more attention should be focused on studying this straining mechanism.

The result that the DBS of B95-G-A-Q was higher than the DBS of B95-G may be attributed to the small grains on the surface generated by the coarsening of the fragments as shown in Fig. 4. This is because it was widely found that the DBS of ceramics decreased with the increasing grain size $[9,19,24]$. Because of tight industrial tolerances, the alumina ceramics which are sealed to metal need to be ground after sintering [25]. High temperature quenching can be used to improve their DBS after the grinding.

It is interesting that annealing improved the DBS of A99. No obvious changes were found in the material characterizations of A99 before and after annealing. The phenomenon could not be attributed to the elimination of defects on the surface, because polishing did not reduce the DBS of A99-AT. More work is needed to find the mechanism behind the effect of annealing on the DBS of A99.

\section{4 Analyses on the underlying mechanisms behind the effects of firing in wet hydrogen}

The improvement of firing in wet hydrogen on the DBS of alumina ceramics can be attributed to the reduction in the concentrations of point defects and electrical carriers. DB is always associated with electrical carriers and their transport [26]. At room temperature, the electrical conductivity is dominant in alumina [27]. For the perfect alumina crystal, the electrical carriers are mainly the electrons in the conduction band and the holes in the valence band that are generated by the thermal excitation. When the electric field is high, space charge limited conduction is the dominant conduction mechanism $[28,29]$. In the thermal DB theory and the avalanche DB theory, the large current induced by the strong electric field can lead to more excited electrical carriers and subsequently the DB. In the recent Schneider's Griffith type energy release rate model for the $\mathrm{DB}$, the conduction mechanism at the tip of filament is also critical to the DB process [30,31]. The improvement of firing in wet hydrogen on the DBS of alumina ceramics might be associated with the reduction in the concentrations of electrical carriers due to the effects of ambient atmosphere on the chemical equilibria of point defects in the alumina ceramics.

Optical characterization is always used to investigate the point defects in the material. In our experiment, firing in wet hydrogen improved reflectance of the three alumina ceramics in the UV region, as shown in Fig. 7 , and the result was consistent with the result of Atlas and Firestone [32]. Firing in wet hydrogen improved the reflectance of the three alumina ceramics in UV region, while it reduced their reflectance in Vis-IR region, making them look darker. Atlas and Firestone [32] attributed the increase in the reflectance in the UV region to the partial elimination of aluminum vacancies. Besides, another proposition is reasonable: the increase in the reflectance in the UV region is attributed to the partial elimination of interstitial oxygen. Lagerlöf and Grimes [33] argued that the interstitial oxygen is the dominant point defect in the pure alumina, and Kozakiewicz et al. [34] found that the interstitial oxygen increased the absorbance of alumina in the UV region. In any case, the increase in the reflectance in the UV region indicates the reduction in the concentration of point defects. The reduction in the concentration of point defects inevitably brings the reduction in the concentration of electrical carriers, which reduces the electrical conductivity.

Firing in wet hydrogen indeed reduced the electrical 


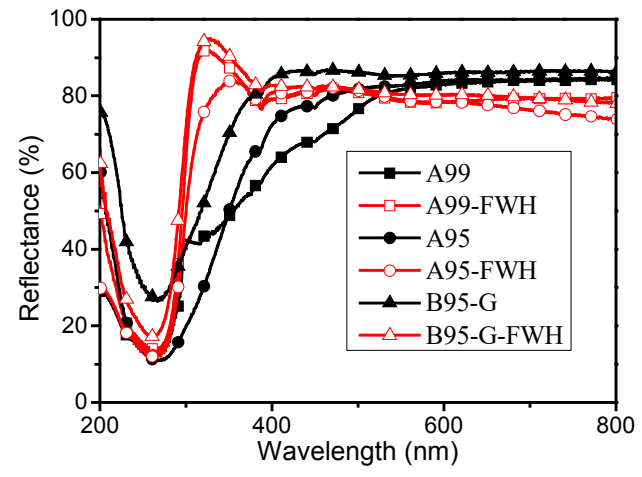

Fig. 7 Reflectance spectra of the alumina ceramics before and after firing in wet hydrogen.

conductivities of A99 and A95 (ESM), and the result was consistent with the result of Pappis and Kingery [10]. The water added into the hydrogen suppressed the generation of electrons (more discussion on the chemical reactions can be found in the ESM). Firing in wet hydrogen improved the DBS of alumina ceramics. On one hand, the alumina ceramics fired in wet hydrogen have a lower concentration of point defects, and under the high electrical field, the concentration of the electrical carriers excited by the incident electrical carriers is lower. On the other hand, the alumina ceramics fired in wet hydrogen have a lower concentration of electrical carriers, and that means the concentration of the incident electrical carriers is lower, leading to a lower concentration of excited electrical carriers under the high electric field. Some other researchers have improved the DBS of inorganic dielectric materials by reducing the concentrations of the point defects. Huang et al. [35] improved the DBS of the $\mathrm{Al}_{2} \mathrm{O}_{3}-\mathrm{SiO}_{2}-\mathrm{TiO}_{2}$ ceramics by doping $\mathrm{Ni}_{2} \mathrm{O}_{3}$, and they attributed the improvement to inhibiting the oxygen vacancies because of the reaction $1 / 2 \mathrm{Ni}_{2} \mathrm{O}_{3} \rightarrow \mathrm{NiO}+1 / 2 \mathrm{O}_{2}$. Yao et al. [36] improved the DBS of the $\mathrm{Al}_{2} \mathrm{O}_{3}$ film by doping $\mathrm{TiO}_{2}$, and they attributed the improvement to the decrease in the oxygen vacancies due to the doping. Much more work on the effect of point defects on the DBS of alumina ceramics is needed.

\section{5 Comparison among the dielectric breakdown strengths of A99-G, A95-G, and B95-G}

Generally, the DBS of alumina ceramics decrease with increasing porosities, which explains why A99-G had the highest DBS among the as-sintered and ground samples. This conclusion is reached because the porosities of A99, A95, and B95 were $1.5 \%, 4.8 \%$ and $6.0 \%$, respectively. The porosity is calculated as $1-\rho / \rho_{0}$, where $\rho$ and $\rho_{0}$ are the actual density and the theoretical density, respectively, and the actual densities are listed in Table 2. The theoretical density of A99 is $3.98 \mathrm{~g} / \mathrm{cm}^{3}$, and the theoretical density of A95 and B95 is about $3.90 \mathrm{~g} / \mathrm{cm}^{3}$. Nevertheless, different arguments on how much the increasing porosity reduced the DBS of alumina ceramics still exist. Liebault et al. [8] reported that the porosities below $5 \%$ had no effect on the DBS of ceramics, and Haddour et al. [37] reported that porosities had weak influence on the DBS of alumina ceramics beyond $92 \%$ densification. However, Neusel et al. [18] found that the increasing porosity still strongly reduced the DBS of an alumina ceramic even when it was below 5\%. There must be some factors causing the differences among the results obtained by Refs. [8,18,37]. In our experiment, A99-G had a much lower porosity than the $95 \%$ alumina ceramics, and the DBS of A99-G was only $8 \%$ higher than the DBS of the ground alumina ceramics. However, the difference seems unnoticeable when it is compared with the differences reported by Ref. [18], in which the DBS of the alumina ceramic of $1.8 \%$ porosity was $38 \%$ higher than the DBS of the alumina ceramic of $6.3 \%$ porosity. Besides, the DBS of A95-G was almost equivalent to the DBS of B95-G, although A95-G had a lower porosity. The result in our experiment was more similar to the result of Ref. [37].

In our recent study, it was found that the DBS of alumina ceramics decreased with the increasing of pores in quantities and sizes [38]. In the study of Ref. [37], with the increasing of the addition of rice starch to the raw powder of alumina ceramics, the porosity and the sizes of pores both increased, so the addition of rice starch had a twofold effect on the DBS of alumina ceramics. However, the alumina ceramics investigated in the study of Ref. [37] were all sintered from compacted powder. Pores in alumina ceramics sintered from compacted powder are always small, and this might be the main reason why our result in this study and the result of Ref. [37] were different from the result of Ref. [18].

\section{Conclusions}

In this study, effects of annealing and firing in wet hydrogen on the DBS of three alumina ceramics were studied. Annealing decreased the DBS of the 95\% alumina ceramics, and improved the DBS of the $99 \%$ 
alumina ceramic. Firing in wet hydrogen improved the DBS of alumina ceramics. The DBS data of the annealed $95 \%$ alumina ceramics cannot be fitted to the Weibull distribution well, and this was different from the previous reports.

The inter-granular phase crystallization that reduced the DBS of the $95 \%$ alumina ceramics after annealing, and the micro-cracks generated by the mismatch between the alumina matrix and crystalline inter-granular phases can be used to explain the phenomenon that was proven by the measurement of bending strengths. However, the correlation between the DB and the mechanical fracture is not so simply through the identical defects such as the microcracks, and this argument was convincingly demonstrated by the comparison between the Weibull distribution fitting in the DB test and the Weibull distribution fitting in the bending strength measurement. No obvious changes were found in the material characterizations of A99 before and after annealing.

For the ground $95 \%$ alumina ceramic, the DBS of the quenched samples was higher than the DBS of as-sintered samples, and the improvement due to quenching on the DBS may be attributed to small grains on the surface generated by the coarsening of fragments.

The improvement of firing in wet hydrogen on the DBS of alumina ceramics can be attributed to the reduction in the concentrations of point defects and electrical carriers, which was convincingly demonstrated by the measurement of reflectance spectra and electrical conductivities.

\section{Acknowledgements}

The study was financially supported by the Science Development Foundation of China Academy of Engineering Physics (2014A0302012) and the Funding Support by Laboratory of Precision Manufacturing Technology, CAEP (ZD18001). The authors also gratefully acknowledge the assistance from Mr. Kang Peng in the DB test. We thank Dr. Yuefang Li for her help in writing the paper.

\section{Electronic Supplementary Material}

Supplementary material is available in the online version of this article at https://doi.org/10.1007/s40145-019-0357-x.

\section{References}

[1] Carter CB, Norton MG. Ceramic Materials. New York,
USA: Springer New York, 2013.

[2] Park CW, Yoon DY. Effects of $\mathrm{SiO}_{2}, \mathrm{CaO}_{2}$, and $\mathrm{MgO}$ additions on the grain growth of alumina. $J$ Am Ceram Soc 2004, 83: 2605-2609.

[3] Baik S, White CL. Anisotropic calcium segregation to the surface of $\mathrm{Al}_{2} \mathrm{O}_{3}$. J Am Ceram Soc 1987, 70: 682-688.

[4] Frueh T, Marker C, Kupp ER, et al. Powder chemistry effects on the sintering of MgO-doped specialty $\mathrm{Al}_{2} \mathrm{O}_{3} . J$ Am Ceram Soc 2018, 101: 2739-2751.

[5] Powell-Dogan CA, Heuer AH. Microstructure of $96 \%$ alumina ceramics: I, characterization of the as-sintered materials. J Am Ceram Soc 1990, 73: 3670-3676.

[6] Powell-Dogan CA, Heuer AH. Microstructure of $96 \%$ alumina ceramics: II, crystallization of high-magnesia boundary glasses. J Am Ceram Soc 1990, 73: 3677-3683.

[7] Powell-Dogan CA, Heuer AH. Microstructure of 96\% alumina ceramics: III, crystallization of high-calcia boundary glasses. J Am Ceram Soc 1990, 73: 3684-3691.

[8] Liebault J, Vallayer J, Goeuriot D, et al. How the trapping of charges can explain the dielectric breakdown performance of alumina ceramics. J Eur Ceram Soc 2001, 21: 389-397.

[9] Touzin M, Goeuriot D, Guerret-Piécourt C, et al. Alumina based ceramics for high-voltage insulation. $J$ Eur Ceram Soc 2010, 30: 805-817.

[10] Pappis J, Kingery WD. Electrical properties of single-crystal and polycrystalline alumina at high temperatures. $J \mathrm{Am}$ Ceram Soc 1961, 44: 459-464.

[11] Miranzo P, Tabernero L, Moya JS, et al. Effect of sintering atmosphere on the densification and electrical properties of alumina. J Am Ceram Soc 1990, 73: 2119-2121.

[12] Damamme G, Le Gressus C, de Reggi AS. Space charge characterization for the 21 th century. IEEE Trans Dielect Electr Insul 1997, 4: 558-584.

[13] Jaitly N, Sudarshan T, Dougal R, et al. Degradation due to wet hydrogen firing on the high-voltage performance of alumina insulators in vacuum applications. IEEE Trans Elect Insul 1987, EI-22: 447-452.

[14] Medvedovski E, Peltsman M. Low pressure injection moulding mass production technology of complex shape advanced ceramic components. Adv Appl Ceram 2012, 111: 333-344.

[15] Gorjan L, Dakskobler A, Kosmač T. Strength evolution of injection-molded ceramic parts during wick-debinding. $J$ Am Ceram Soc 2012, 95: 188-193.

[16] ASTM D149-97a(2004). Test method for dielectric breakdown voltage and dielectric strength of solid electrical insulating materials at commercial power frequencies. ASTM International. DOI 10.1520/d0149-97ar04.

[17] Block B, Kim Y, Shetty DK. Dielectric breakdown of polycrystalline alumina: A weakest-link failure analysis. $J$ Am Ceram Soc 2013, 96: 3430-3439.

[18] Neusel C, Jelitto H, Schmidt D, et al. Thickness-dependence of the breakdown strength: Analysis of the dielectric and mechanical failure. J Eur Ceram Soc 2015, 35: 113-123.

[19] Carabajar S, Olagnon C, Fantozzi G, et al. Relations 
between electrical breakdown field and mechanical properties of ceramics. In Proceedings of 1995 Conference on Electrical Insulation and Dielectric Phenomena, Virginia Beach, VA, USA, 1995: 278-281.

[20] Malec D, Bley V, Talbi F, et al. Contribution to the understanding of the relationship between mechanical and dielectric strengths of Alumina. J Eur Ceram Soc 2010, 30: 3117-3123.

[21] Tomaszewski H. Effect of the intergranular phase structure on the thermomechanical properties of alumina ceramics. Ceram Int 1988, 14: 93-99.

[22] Padture NP, Chan HM. Improved flaw tolerance in alumina containing 1 vol\% anorthite via crystallization of the intergranular glass. J Am Ceram Soc 1992, 75: 1870-1875.

[23] Jouini Z, Malec D, Valdez-Nava Z. Effect of mechanical prestress on the dielectric strength of alumina. In Proceedings of the 2016 IEEE International Conference on Dielectrics (ICD), Montpellier, France, 2016.

[24] Beauchamp EK. Effect of microstructure on pulse electrical strength of MgO. J Am Ceram Soc 1971, 54: 484-487.

[25] German RM, Suri P, Park SJ. Review: liquid phase sintering. J Mater Sci 2009, 44: 1-39.

[26] Blaise G. Charge localization and transport in disordered dielectric materials. J Electrost 2001, 50: 69-89.

[27] Will FG, de Lorenzi HG, Janora KH. Conduction mechanism of single-crystal alumina. J Am Ceram Soc 1992, 75: 295-304.

[28] Talbi F, Lalam F, Malec D. DC conduction of $\mathrm{Al}_{2} \mathrm{O}_{3}$ under high electric field. J Phys D: Appl Phys 2007, 40: 3803-3806.

[29] Neusel C, Jelitto H, Schneider GA. Electrical conduction mechanism in bulk ceramic insulators at high voltages until dielectric breakdown. J Appl Phys 2015, 117: 154902.

[30] Schneider GA. A Griffith type energy release rate model for dielectric breakdown under space charge limited conductivity. J Mech Phys Solids 2013, 61: 78-90.

[31] Fischer PK, Schneider GA. Dielectric breakdown toughness from filament induced dielectric breakdown in borosilicate glass. J Eur Ceram Soc 2018, 38: 4476-4482.

[32] Atlas LM, Firestone RF. Application of thermoluminescence and reflectance methods to study of lattice defects in alumina ceramics. J Am Ceram Soc 1960, 43: 476-483.

[33] Lagerlöf KPD, Grimes RW. The defect chemistry of sapphire $\left(\alpha-\mathrm{Al}_{2} \mathrm{O}_{3}\right)$. Acta Mater 1998, 46: 5689-5700.

[34] Kozakiewicz AG, Davidson AT, Derry TE. VUV optical absorption in sapphire crystals following implantation with $100 \mathrm{keV} \mathrm{O}+, \mathrm{Al}+$ and $\mathrm{Cr}+$ ions. Nucl Instruments Methods Phys Res Sect B: Beam Interactions Mater Atoms 2002, 191: 582-585.

[35] Huang $\mathrm{Y}$, Chen $\mathrm{Y}$, Li X, et al. Enhanced dielectric breakdown strength in $\mathrm{Ni}_{2} \mathrm{O}_{3}$ modified $\mathrm{Al}_{2} \mathrm{O}_{3}-\mathrm{SiO}_{2}-\mathrm{TiO}_{2}$ based dielectric ceramics. J Eur Ceram Soc 2018, 38: 3861-3866.

[36] Yao MW, Xiao RH, Peng Y, et al. The influence of titanium doping on the electric properties of amorphous alumina films prepared by sol-gel technology. J Sol-Gel Sci Technol 2015, 74: 39-44.

[37] Haddour L, Mesrati N, Goeuriot D, et al. Relationships between microstructure, mechanical and dielectric properties of different alumina materials. $J$ Eur Ceram Soc 2009, 29: 2747-2756.

[38] Zhang T, Lei YJ, Yin J, et al. Effects of pores on dielectric breakdown of alumina ceramics under AC electric field. Ceram Int 2019, 45: 13951-13957.

Open Access This article is licensed under a Creative Commons Attribution 4.0 International License, which permits use, sharing, adaptation, distribution and reproduction in any medium or format, as long as you give appropriate credit to the original author(s) and the source, provide a link to the Creative Commons licence, and indicate if changes were made.

The images or other third party material in this article are included in the article's Creative Commons licence, unless indicated otherwise in a credit line to the material. If material is not included in the article's Creative Commons licence and your intended use is not permitted by statutory regulation or exceeds the permitted use, you will need to obtain permission directly from the copyright holder.

To view a copy of this licence, visit http://creativecommons. org/licenses/by/4.0/. 